Research Article

\title{
Influence of Upstream and Downstream Compressor Stators on Rotor Exit Flow Field
}

\author{
Nicole L. Key \\ School of Mechanical Engineering, Purdue University, 500 Allison Road, West Lafayette, IN 47907, USA \\ Correspondence should be addressed to Nicole L. Key; nkey@purdue.edu
}

Received 19 March 2014; Accepted 17 September 2014; Published 8 October 2014

Academic Editor: Ting Wang

Copyright (c) 2014 Nicole L. Key. This is an open access article distributed under the Creative Commons Attribution License, which permits unrestricted use, distribution, and reproduction in any medium, provided the original work is properly cited.

\begin{abstract}
Measurements acquired at the rotor exit plane illuminate the interaction of the rotor with the upstream vane row and the downstream vane row. The relative phase of the upstream and downstream vane rows is adjusted using vane clocking so that the effect of the upstream propagating potential field from the downstream stator can be distinguished from the effects associated with the wakes shed from the upstream stator. Unsteady absolute flow angle information shows that the downstream potential field causes the absolute flow angle to increase in the vicinity of the downstream stator leading edge. The presence of Stator 1 wake is also detected at this measurement plane using unsteady total pressure data. The rotor wakes are measured at different circumferential locations across the vane passage, and the influence of Stator 1 wake on the suction side of the rotor wake is evident. Also, the influence of the downstream stator is detected on the pressure side of the rotor wake for a particular clocking configuration. Understanding the role of the surrounding vane rows on rotor wake development will lead to improved comparison between experimental data and results from computational models.
\end{abstract}

\section{Introduction}

The inherently unsteady turbomachinery flow field resulting from the presence of stationary vane rows and rotating blade rows gives rise to blade row interactions that affect performance and unsteady forcing that can lead to high cycle fatigue. Blade row interactions include the wakes shed from upstream blade and vane rows. These viscous wakes convect with the flow field and get turned and distorted as they are chopped by downstream rows. Blade row interactions also include the potential fields associated with both upstream and downstream blade rows. The potential fields typically decay in an exponential manner and, thus, only affect the neighboring rows.

Blade row interactions have been investigated in multistage compressor research facilities. For instance, researchers investigated the unsteady boundary layer behavior on the first stage stator using arrays of surface-mounted hot-film sensors to characterize the unsteady wall shear stress. The vane boundary layer development was strongly influenced by the incoming rotor wakes. The potential field from the downstream rotor blade row was less important to boundary layer transition. The potential field of the downstream blade row, however, had a large influence on the surface pressure distribution. The unsteady blade circulation changed for every passing of the rotor blade of both the upstream and the downstream blade rows [1].

Every time a rotor airfoil passes near the downstream stator's leading edge, the rotor performs additional work to achieve the higher static pressures in the vicinity of the vane leading edge [2]. Compared to an isolated rotor at the same overall pressure rise, time-averaged rotor loss can increase by $20-40 \%$ due to the variation in backpressure imposed by the downstream stator, as shown by some computational models [3]. In cases where the downstream stator has a significant corner separation, the rotor wake fluid creates an unsteady loading on stator vanes. This can lead to an unsteady pressure field resulting in unsteady secondary flows near the hub. In one study at high loading conditions, the rotor wake was amplified near the boundaries of the hub corner separation [4].

The phase of the upstream and downstream potential fields can be adjusted in certain experimental facilities where the vanes can be circumferentially indexed. This has been 
done to study vane clocking, the circumferential indexing of adjacent vane rows with similar vane counts. Researchers have shown that vane clocking can impact stage loss and efficiency by changing the amount of interaction the upstream vane wakes have with the downstream vane boundary layer [5-8]. In this research, clocking is used to isolate the flow field effects associated with the downstream vane potential field.

This change in phase of the potential fields between the upstream and the downstream vane rows can affect the unsteady forces acting on a rotor. Researchers have shown that vane clocking can have a large impact on the unsteady aerodynamic forcing function, primarily the chordwise gust, in an axial compressor [9]. Vane clocking effects on the embedded rotor's resonant response for a Campbell diagram crossing at the first torsion mode were measured with a tip timing system [10], and CFD predictions matched the measured cyclic trend of rotor response with vane clocking configuration, where the rotor tip deflection decreased by as much as $33 \%$ with vane clocking [11]. A $60 \%$ reduction in the stator force amplitude was measured in a rotor-stator-rotor large-scale, low-speed axial compressor by clocking the downstream rotor. The position resulting in minimum vane response occurred when the maximum force caused by the upstream rotor wake coincided with the minimum force created by the downstream rotor potential field. The maximum vortical gust occurred when the rotor wake was chopped by the stator blade leading edge [12].

One experimental study on vane clocking performance benefits was conducted in a transonic compressor consisting of 34 IGVs, 35 rotor blades, and 34 vanes. To determine the role of potential field interactions in vane clocking, the axial gap between the rotor and the stator was reduced by $67 \%$. For the large gap, the overall change in efficiency with clocking was $1 \%$ but increased to $1.4 \%$ for the smaller gap [13]. A full annulus simulation of this machine indicated that a change in the strength of the rotor wake was one of the dominant effects of vane clocking. The computational results indicate that the performance increase measured in the experiments was associated with both increased rotor work and reduced stator loss [14].

The objective of this research is to improve the understanding of the effects of the surrounding vane rows on the embedded rotor. The effect of the downstream vane potential field will be isolated by indexing the vanes to two different clocking configurations that are out-of-phase with each other. Detailed flow field traverses with fast-response instrumentation are accomplished by traversing all vanes past the stationary probes in a prescribed clocking configuration. High resolution (50 points across one vane passage) in the pitchwise direction allows for the potential field effects to be determined. The effect of the upstream stator wake on the rotor performance is also explored. The high resolution of data in the pitchwise direction is not commonly found in the literature, and thus this paper is one of the few that are able to look at how the vane potential field affects rotor wake shape, which has important implications as the forcing function to the downstream vane row. Any improved understanding of these blade row interactions will be useful
TABLE 1: The Purdue 3-Stage Compressor design airfoil parameters.

\begin{tabular}{lccccccc}
\hline & IGV & R1 & S1 & R2 & S2 & R3 & S3 \\
\hline \# of blades & 44 & 36 & 44 & 33 & 44 & 30 & 50 \\
Solidity & 1.27 & 1.37 & 1.34 & 1.33 & 1.42 & 1.28 & 1.70 \\
AR & 1.00 & 0.76 & 0.95 & 0.72 & 0.90 & 0.68 & 0.85 \\
Mach & 0.26 & 0.46 & 0.35 & 0.45 & 0.33 & 0.44 & 0.31 \\
number & (abs) & (rel) & (abs) & $\begin{array}{c}\text { (rel) } \\
\text { (abs) }\end{array}$ & $\begin{array}{l}\text { (rel) } \\
\text { (abs) }\end{array}$ \\
\hline
\end{tabular}

for developing and validating models utilized in multistage compressor calculations.

\section{Experimental Approach}

This research was performed in the Purdue 3-Stage Research Compressor which features geometry representative of the rear stages of a high pressure compressor, with engine representative of Mach numbers and Reynolds numbers [15]. For these experiments, atmospheric air was drawn into the test cell through screened doors and entered the compressor via an inlet bell mouth. The compressor was throttled with a sliding cone at the compressor exit. It is scaled up (24-inch tip diameter) with a hub-to-tip ratio of 0.833 and consists of an IGV followed by three stages. The IGVs and all blades are of double circular arc designs, and the remaining vanes are NACA 65-series airfoils. Other airfoil parameters are listed in Table 1, including airfoil count showing that the IGV and first two vane rows have 44 vanes. The embedded Rotor 2 blade row is the focus of this study, and it is surrounded by vane rows with identical vane counts, allowing for clocking which adjusts the phase of the potential fields between the upstream and the downstream vane rows.

The vane rows are individually indexable, allowing the vanes to be traversed past stationary instrumentation in a specified clocking configuration to obtain data in the pitchwise direction. The repeatability of the vane position measurement system with precision string potentiometers is better than $0.1 \%$ of the vane passage. The vanes were indexed in a pattern such that the vanes moved half a passage in successive measurements. For example, rather than measuring in ascending vane passage position, optimum control of vane position for the mechanical system responsible for vane movement occurred when measured in a pattern such as $5 \%, 55 \%, 7 \%$, and $57 \%$ vp. Thus, if measurement drift should occur, it would be noticed by an abnormal and "chopped" profile.

Vane clocking effects have been studied in great detail in this compressor, with a large focus on the effect of vane clocking on stator loss and thus stage performance $[8,16]$. With similar vane counts for the IGV, S1, and S2, the effects of vane clocking can be isolated on the embedded stage by clocking S1 with respect to S2. For these studies, the relative position of the IGV and S1 was held constant as was the relative position of S2 and S3. The two clocking configurations that are presented in this paper are illustrated in Figure 1 where one clocking configuration leads to wake impingement on the downstream vane row $\left(\mathrm{CL}_{\mathrm{LE}}\right)$ while 

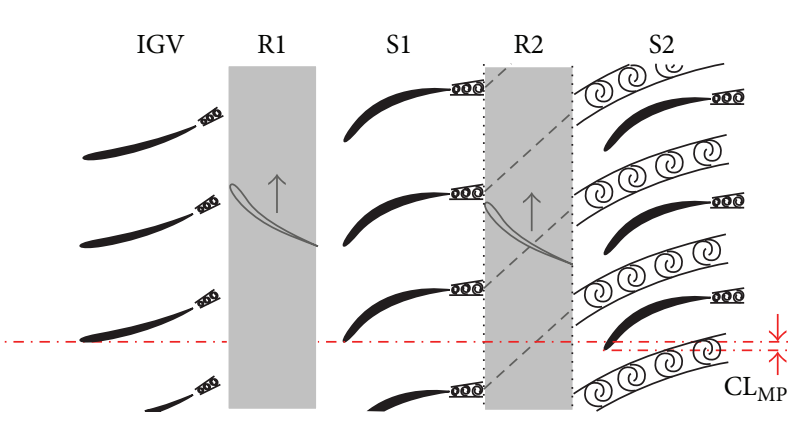

(a)
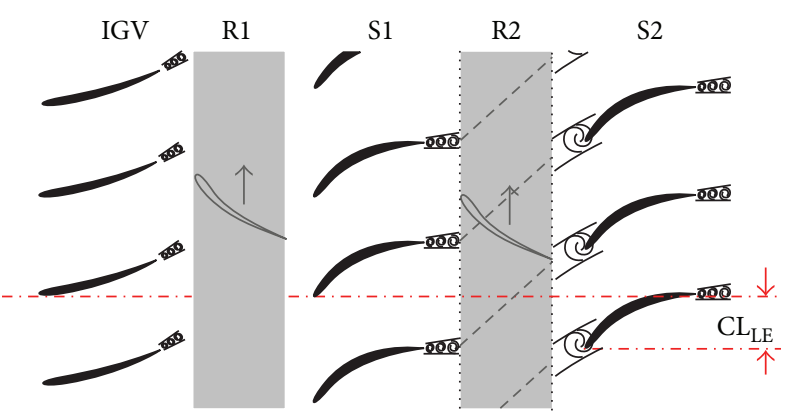

(b)

FIgURE 1: The two clocking configurations studied in detail in the Purdue 3-Stage Research Compressor.

the other one, half a passage out of phase with the first, allows the wakes to pass through the downstream passages $\left(\mathrm{CL}_{\mathrm{MP}}\right)$. The clocking configuration is defined as the position of Stator 1 minus the position of Stator 2 in terms of \% vane passage (vp). The two clocking configurations in this paper are called CL3 and CL6 and represent offsets of 32\%vp and $83 \% v p$, respectively. Previous results show that at design loading, S1 wake impingement on S2 (CL3) reduces S2 loss. While vane clocking does not impact the time-averaged rotor performance, as documented in [17], the current paper presents rotor exit data acquired for these two clocking configurations to show how the surrounding stators impact the rotor flow field.

All results are acquired at $100 \%$ corrected design speed, $5,000 \mathrm{rpm}$. The data presented in this paper are acquired at the design point, and some data are also shown for a high loading condition. The design point is characterized as the highest efficiency condition. At a particular loading condition, data for both clocking configurations were acquired during the same run, where the vanes were traversed, in a specified clocking configuration, past the instrumentation to obtain pitchwise information. Variations in steady operating point within a test and for different tests were small. During any given test, the largest standard deviation in corrected mass flow rate was less than $0.5 \%$ of the tested flow rate, and the largest standard deviation in total pressure ratio was less than $0.15 \%$ of the tested conditions. All of the data presented in this paper were acquired on days of similar ambient temperature and humidity resulting in nearly constant (within 2.5\%) blade Reynolds numbers. By choosing a day of stable atmospheric pressure, the compressor operating point was set after approximately one hour of run time, which was sufficient to reach steady state operation. Once the throttle position was set, it was not adjusted until all passage data for both clocking configurations were acquired, typically resulting in a run duration of 4 hours. As the inlet total temperature changed, the compressor mechanical speed was adjusted to keep the compressor operating within $\pm 5 \mathrm{rpm}$ of a corrected speed of 5,000 rpm.

The high loading case is of interest because the potential field is stronger at this condition. Figure 2 shows the casing static pressure half way between the Rotor 2 trailing edge and the Stator 2 leading edge, which is the measurement plane

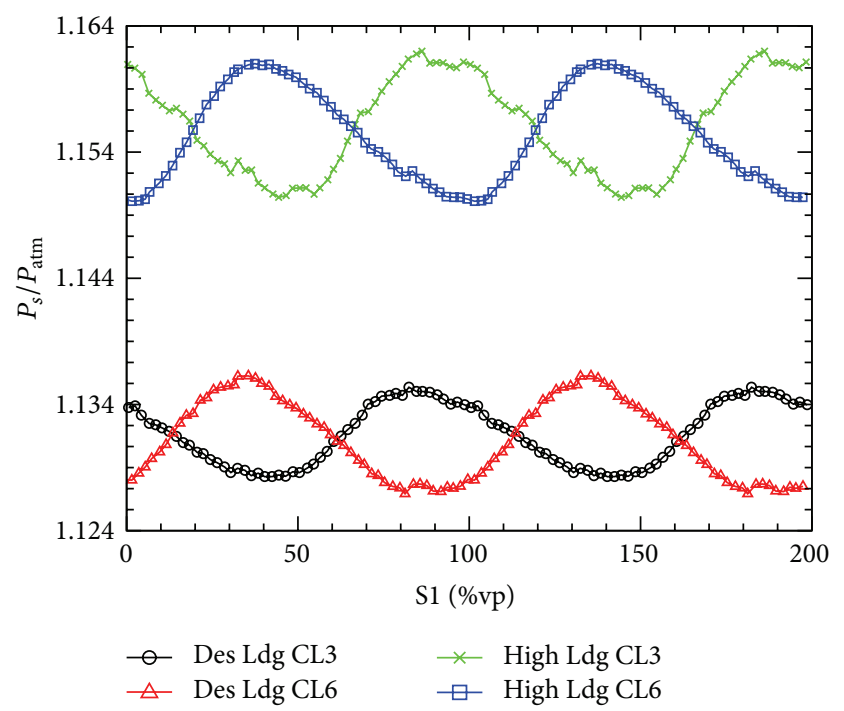

FIGURE 2: Casing static pressure at Rotor 2 exit for both clocking configurations at design and high loading.

for all the data presented in this paper. The abscissa is the circumferential position with respect to Stator 1 vanes, where two vane passages are shown assuming periodicity. The casing pressures shown in Figure 2 were acquired at design point and high loading for two clocking configurations, CL3 and CL6. These clocking configurations are half a vane passage out of phase with each other. This figure shows that in addition to increasing the mean pressure with high loading, the potential field variation associated with the downstream vanes increases by about 15\% for the high loading case.

A TSI Inc. IFA 100 constant temperature tnemometer with a TSI model 1247A-10 miniature platinum cross-film sensor was used to acquire instantaneous flow angle and velocity information in the axial-circumferential plane. Heat transfer from the sensor to the fluid is affected by the total temperature, velocity, and density of the flow. A complete calibration of the two film voltages was acquired over all expected flow angles and velocities for a given total temperature and density. A correction for the difference in mean total temperature and density between the calibration conditions and the experimental conditions was developed 


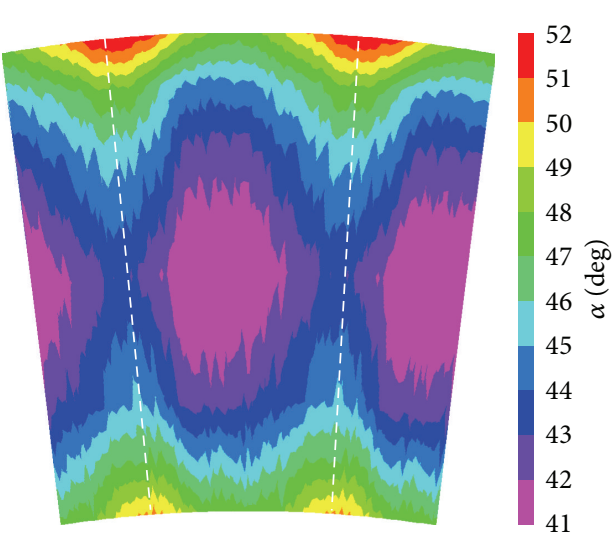

(a)

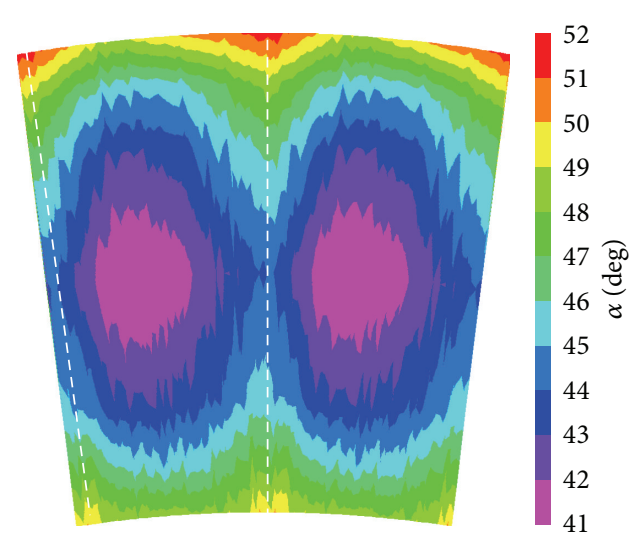

(b)

Figure 3: Time averaged absolute flow angle at Rotor 2 exit for CL3 (a) and CL6 (b).

in a compressible calibration jet facility where pressures upstream and downstream of an orifice plate were computer controlled to provide the desired jet velocity at the desired density. A heater upstream of the orifice plate controlled the jet temperature as well. Therefore, a correction based on mean density and total temperature (as measured by rakes and static pressure) was applied to the measured sensor voltages at each vane position. All time-accurate data were acquired at a sampling frequency of $120 \mathrm{kHz}$, with 200 revolutions of data used to characterize an ensemble averaged revolution. Preliminary tests showed that using a larger number of rotor revolutions did not decrease the standard deviations associated with ensemble averaging.

The steady radial flow angle was measured with a five-hole probe. Results in this paper are shown at 30\%, 50\%, and $70 \%$ span. The mean rotor exit radial flow angle at these spanwise locations and for both operating conditions is less than $1.5^{\circ}$ in magnitude. Thus, there is not a significant radial component of the flow velocity at these locations, and the use of a crossfilm sensor is adequate. The uncertainty in the tangential flow angle measurements acquired with the cross-film sensors is $\pm 1^{\circ}$. The largest sources of uncertainty are the alignment of the probe (which contributes to a DC offset), and also a shift in the calibration parameters has been noted during runs when the film gets contaminated with an oily substance, but the results remain within the uncertainty band of $\pm 1^{\circ}$.

Other types of fast-response instrumentation include a high-sensitivity miniature fast-response pressure transducer manufactured in a Kiel head total pressure probe to acquire unsteady total pressure measurements. This measurement has an uncertainty of $\pm 0.17 \mathrm{kPa}$, and the size of the probe head is less than $4 \%$ of the blade span.

\section{Rotor Exit Flow Field}

The absolute flow angle at Rotor 2 exit/Stator 2 inlet is shown in Figure 3 for both clocking configurations. The only difference between the two cases is the position of the downstream Stator 2 vanes. The white dashed line indicates the circumferential location of the downstream Stator 2 vane

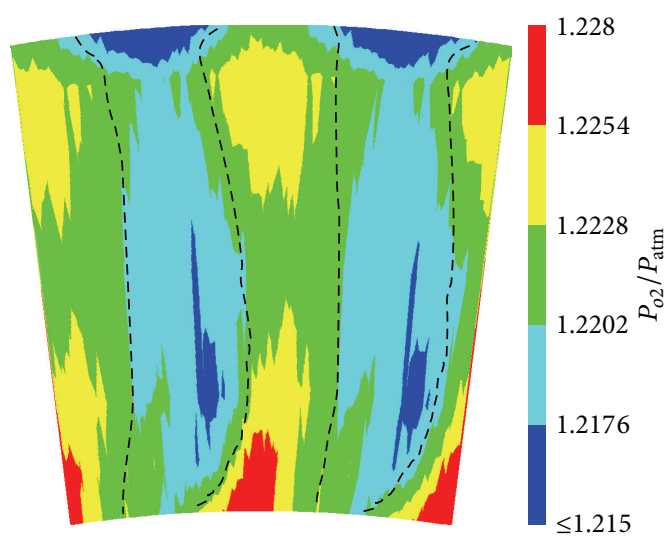

FIGURE 4: Time-averaged total pressure at the Rotor 2 exit plane.

leading edge. The axial distance between the probe and the downstream vane leading edge is less than $15 \% \mathrm{c}$. These data were acquired with cross-film thermal anemometry sensors. Data were acquired at 50 positions across one vane pitch to fully capture the effect of the downstream vane potential field. Two vane passages are shown assuming periodicity. Data were acquired at 8 radial locations $(12 \%, 20 \%, 30 \%, 50 \%$, $70 \%, 80 \%$, and $88 \%$ span). Data are not extrapolated to the endwalls.

For a given spanwise location the change in absolute flow angle across the passage is 3 to 4 degrees except at $12 \%$ span, where the variation is smaller and closer to 2 degrees. The highest flow angle occurs in the region near the vane leading edge. The increased flow angle near the leading edge is also accompanied by a slight decrease in axial velocity and a slight increase in tangential velocity, $V_{\theta}$. This higher flow angle corresponds to regions of higher static pressure (shown in Figure 1). These results compare well with those from Hall [2] who showed that the rotor performs additional work to achieve the higher static pressures in the vicinity of the vane leading edge.

The upstream vane (Stator 1) wake is apparent in the total pressure field at the Rotor 2 exit/Stator 2 inlet, Figure 4. 


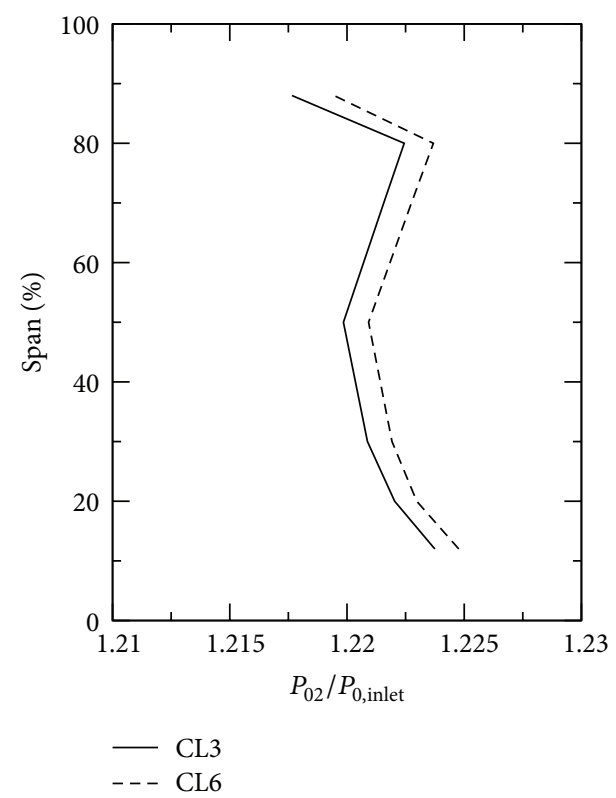

FIGURE 5: Radial total pressure profiles at the rotor exit for both clocking configurations.

Data were acquired with a high frequency response pressure transducer embedded in a Kiel head probe that was traversed to the same 7 radial locations while the vanes were traversed in $2 \% \mathrm{vp}$ increments past the probe in both clocking configurations. The time-averaged total pressure field at Rotor 2 exit plane is shown in Figure 4. The rotor exit total pressure field is fairly uniform. The range of the total pressure measurements is on the order of $1 \%$ of the mean total pressure. Nevertheless, Stator 1 wake position is detected as the nearly radial total pressure deficit, and it is outlined using black dashed lines. Only the result for clocking configuration 3 is shown because the other clocking configuration is nearly identical to this. Thus, the effect of the downstream potential field is not detected in the timeaveraged total pressure field. The difference in the radial total pressure profiles between the two clocking configurations is shown in Figure 5. These profiles were calculated by taking a pitchwise average of the time-averaged total pressure. The shape of the two profiles is nearly identical. An offset of about $0.2 \%$ is shown between the two cases and this is within the uncertainty of the measurement.

Therefore, at Rotor 2 exit, the two important steady flow field features are Stator 1 wakes, which appear near 60\%vp with respect to Stator 1 coordinate system, and potential field set up by the Stator 2 leading edge. However, these steady flow field features will play a role in the development of the rotor wakes. The unsteady flow field associated with the rotor wakes will be investigated in the next section.

\section{Rotor Wakes}

Rotor wakes are a deficit in the relative frame velocity. Figure 6 shows how this relative frame velocity deficit manifests itself as an increase in absolute flow angle. Since

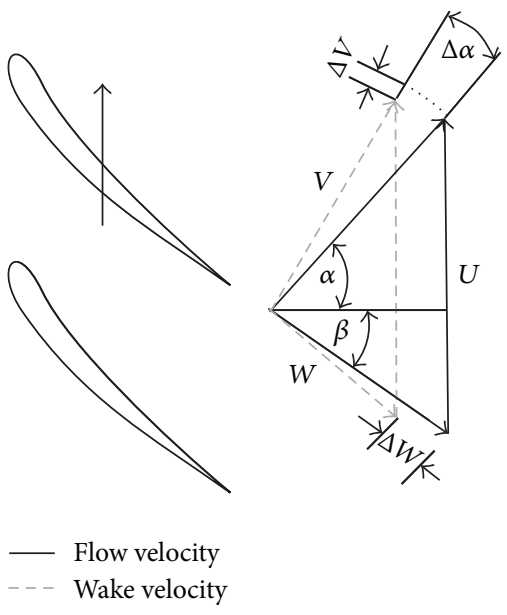

FIGURE 6: Rotor exit velocity triangle including rotor wake.

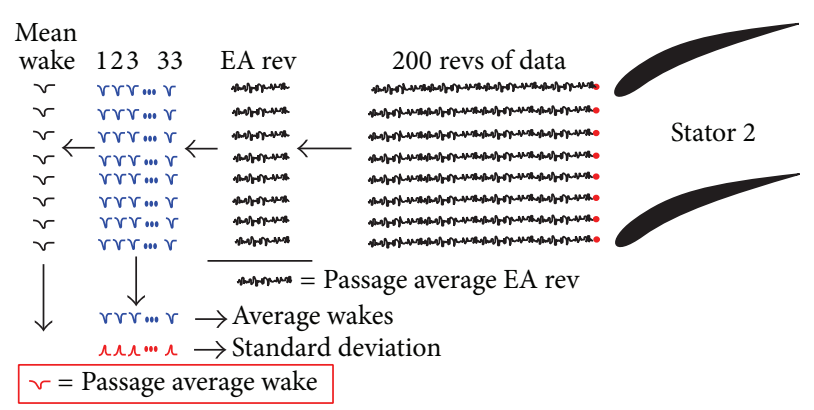

FIGURE 7: Data processing strategy for cross-film measurements acquired at rotor exit.

the unsteady flow angle was directly measured with the crossfilm sensor, the rotor wakes are presented in terms of absolute flow angle. The data processing strategy for the unsteady rotor exit flow angle measurements is shown in Figure 7. At each circumferential and radial position, 200 revolutions of cross-film data are acquired simultaneously with a once-perrevolution shaft trigger. This allows a phase-locked ensemble average (EA) revolution of data to be determined. The passage average wake was calculated by determining the mean wake at each circumferential position. Then, the 50 mean wakes across the vane passage were averaged to provide the passage average wake. This data processing strategy has been successfully used in the past to sort out rotor wake variations due to rotor-rotor interactions versus vane potential field interactions [18].

Figure 8 shows the passage average wakes at 30\%, 50\%, and $70 \%$ span for both clocking configurations at design loading and high loading, as calculated per the method described in Figure 7. At design loading, Rotor 2 wake profiles for CL6 are shifted toward higher normalized time. The flow angle levels also seem shifted to slightly higher values for CL6. The uncertainty associated with the cross-film measurements is $\pm 1^{\circ}$, and the differences shown in Figure 8 fall within this uncertainty. The results at high loading are considered since the potential field associated with Stator 2 is stronger at this loading condition, as was shown in Figure 1. 


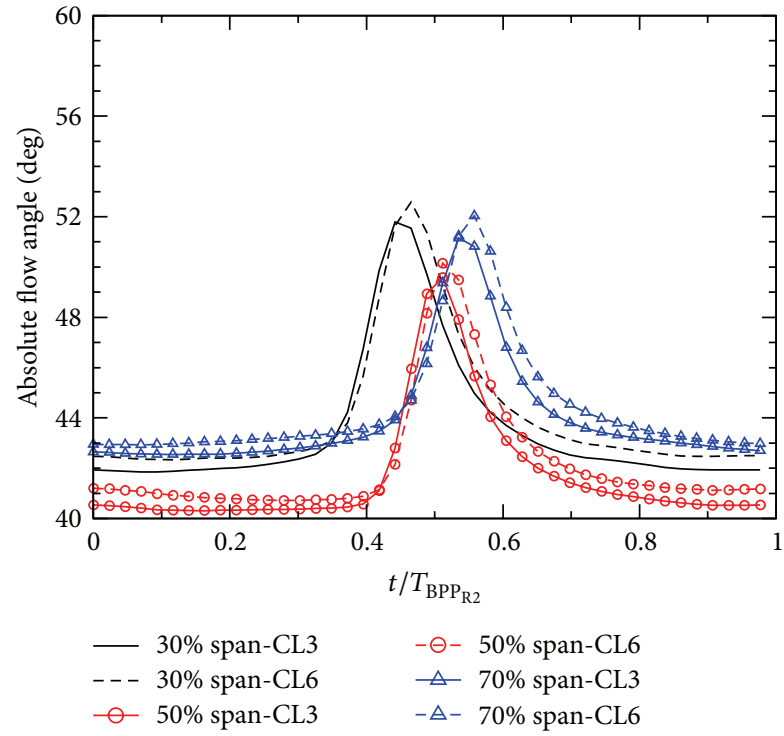

(a)

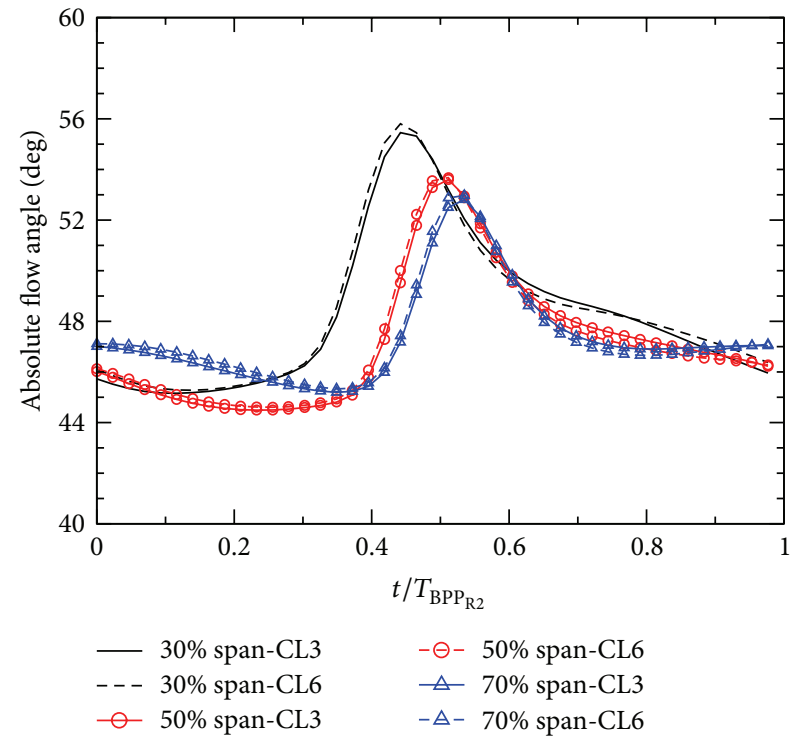

(b)

FIGURE 8: Passage average Rotor 2 wake at design loading (a) and high loading (b).

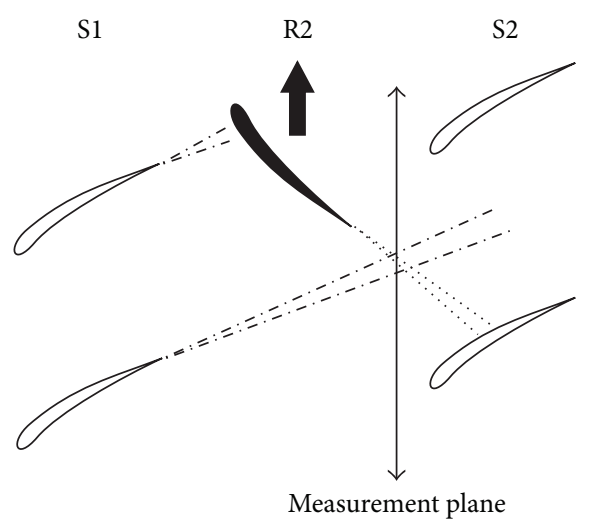

(a)

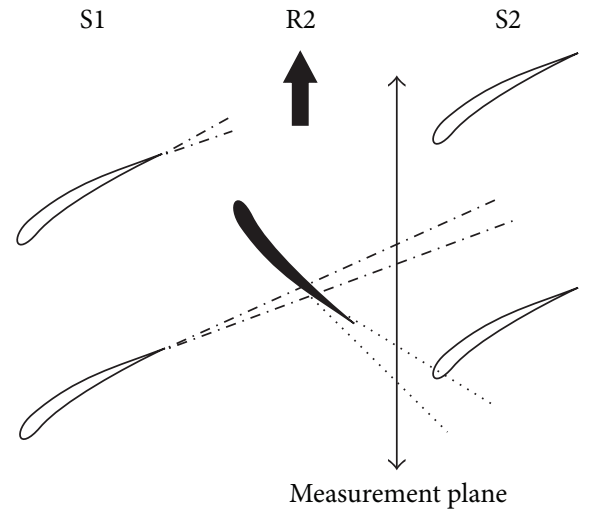

(b)

Figure 9: Cartoon describing Stator 1 wake and Rotor 2 interactions for CL6, in particular.

Results for the passage average wake at $30 \%, 50 \%$, and $70 \%$ span for the high loading condition show even less variation in the R2 wakes between the two clocking configurations compared to that at design loading. In fact, the repeatability between the CL3 and CL6 wakes is remarkable. These data were acquired during a 4-hour run and thus these results indicate the very steady operation of the facility over this time frame. Also, Rotor 2 wakes for CL3 and CL6 at high loading are the most similar of all cases measured (including R1 wakes which are not shown in this paper). It is unclear what led to the offset shown in Rotor 2 wakes at design loading, but there is no evidence to support that it was associated with Stator 2 potential field effects. Since the offset shown at design loading for the Rotor 2 wakes is very uniform for all spanwise loading conditions, it is likely that some shift in hot-film voltages due to film contamination is the most likely reason for the offset. If it was a potential field effect, there would be larger differences shown at high loading, but that is not the case. This supports the notion that it is associated with the instrumentation rather than a flow field phenomenon such as potential fields.

The average flow angle for each case was calculated by taking the area (or time) average of the passage average wake. The largest difference in flow angle occurs at design loading for Rotor 2. However, at high loading, Rotor 2 exit flow angle has a $0.06 \%\left(0.03^{\circ}\right)$ difference between the two S2 positions at $70 \%$ span. All of the differences in flow angles between the two clocking configurations, CL3 and CL6, are less than $0.5^{\circ}$, less than half of the uncertainty in the flow angle measurements. Thus, there is no measurable change in time average and passage average turning through the rotor with Stator 2 position, and it can be concluded that the work input to the flow by Rotor 2 is the same for both clocking configurations.

Figure 9 shows a cartoon indicating how the upstream vane wakes from Stator 1 can influence the boundary layer 


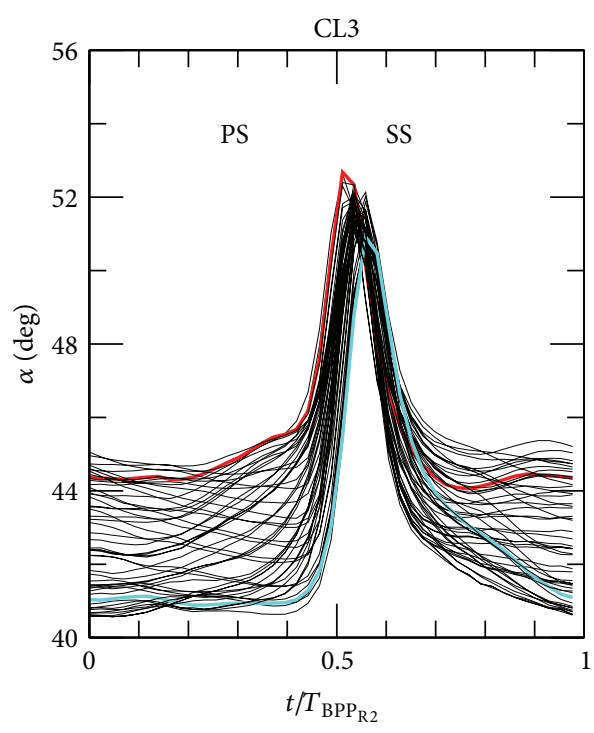

(a)

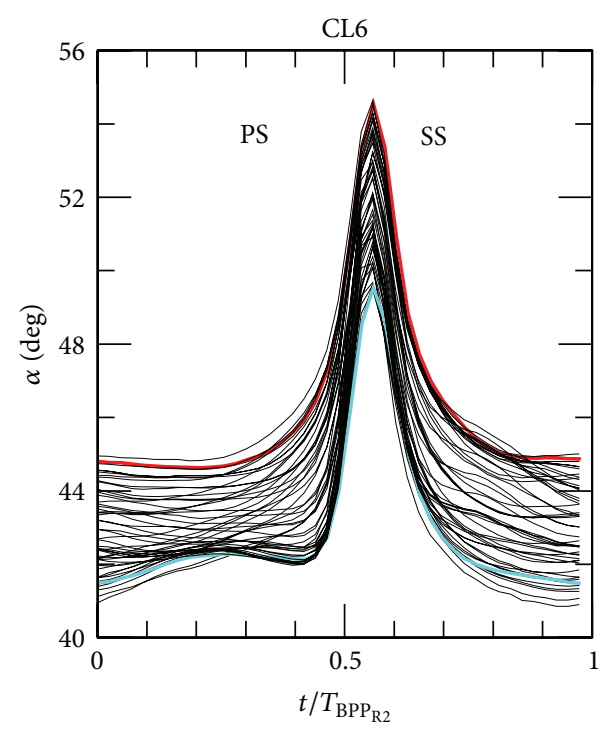

(b)

FIGURE 10: R2 mean wakes at 70\% Span. The red wake was measured near the S2 LE, and the blue wake near midpassage.

growth and shedding in the wake from the suction side of Rotor 2. In the cartoon on the left, the rotor has just chopped Stator 1 wake. Stator 1 wakes also intersect with Rotor 2 wakes. The vertical line represents the measurement plane where the unsteady data are acquired. When the probe is sitting at the circumferential location that places it in Stator 1 wake, there will be portions of time when the probe is only measuring Stator 1 wake and when the rotor passes by, there will be portions of time it measures the interaction of the Rotor 2 wake with the Stator 1 wake. Next, consider the cartoon on the right in Figure 9. At certain probe locations, Stator 1 wake will be impinging on the suction side of Rotor 2, some distance from the leading edge. At some location along the suction side (at some time of the rotor blade passing), Stator 1 wake could trip Rotor 2 boundary layer which could change the shedding in the suction side of Rotor 2 wake. Thus, as drawn in this cartoon, when the stationary probe is near Stator 2 leading edge, it could be measuring fluctuations off the suction side rotor wake associated with the impingement of Stator 1 wake. In this sketch, since Stator 2 leading edge also happens to be here, it would be possible to come to the wrong conclusion that the S2 potential field is causing this effect. Thus, it is important to be able to adjust the phasing between Stator 1 and Stator 2 to understand the source of any rotor wake differences measured across the vane passage. The precise wake path will also be affected by secondary flows, but this is a simplified cartoon that illustrates the first-order effects on wake convection and interaction.

The unsteady flow angle data are processed to illuminate how Rotor 2 wake shape changes with circumferential position across the vane passage to illuminate the effects shown in Figure 9. The mean wake at each circumferential position is calculated, as shown in Figure 7. Differences in rotor wake shape associated with circumferential position across the vane passage are shown by comparing the mean wake at all circumferential positions.
The mean wake at 50 points across the vane passage at $70 \%$ span for design loading is shown in Figure 10 for both clocking configurations. The mean wake measured in front of Stator 2 leading edge is shown in red. The mean wake measured half a vane passage from Stator 2 leading edge is shown in blue. The mean wake under the influence of Stator 2 leading edge (red) has larger flow angles associated with the potential field. The mean flow angle is larger in this region and provides an offset to the wake measured in the middle portion of the passage. The comparison between the red wake and the blue wake for CL3 is a good example of how the suction side shedding of the wake differs with position across the passage. As shown in Figure 9, this is likely due to the change in the location of Stator 1 wake impingement on the suction side of the rotor leading to different rotor suction side boundary layer development which is then measured in the suction side shedding of the rotor wake.

The rotor wake depth is calculated for the mean wakes at each of the circumferential positions across the vane passage for both clocking configurations, and this is shown in Figure 11. Wake depth is defined as the difference between the maximum flow angle value within the wake and the flow angle in the freestream. The wake depth changes by almost 3 degrees with respect to circumferential position across the vane passage. There is a negligible difference in the wake depths measured for the two clocking configurations. The abscissa is shown with respect to Stator 1 coordinate system, and thus the difference between the two series is the relative location of Stator 2 leading edge, which cannot be detected. The wake depth is the lowest near $48 \%$ vp. Stator 1 wake is located near $60 \% \mathrm{vp}$ at this measurement plane, and thus it is not associated with the minimum wake depth either. Figure 4 shows that S1 wake is wide and diffuse by the time it reaches this plane, located in the range of $40-80 \% \mathrm{vp}$ in $\mathrm{S} 1$ coordinate system, as used in Figure 11. The minimum wake depth is created when the rotor blade interacts with 


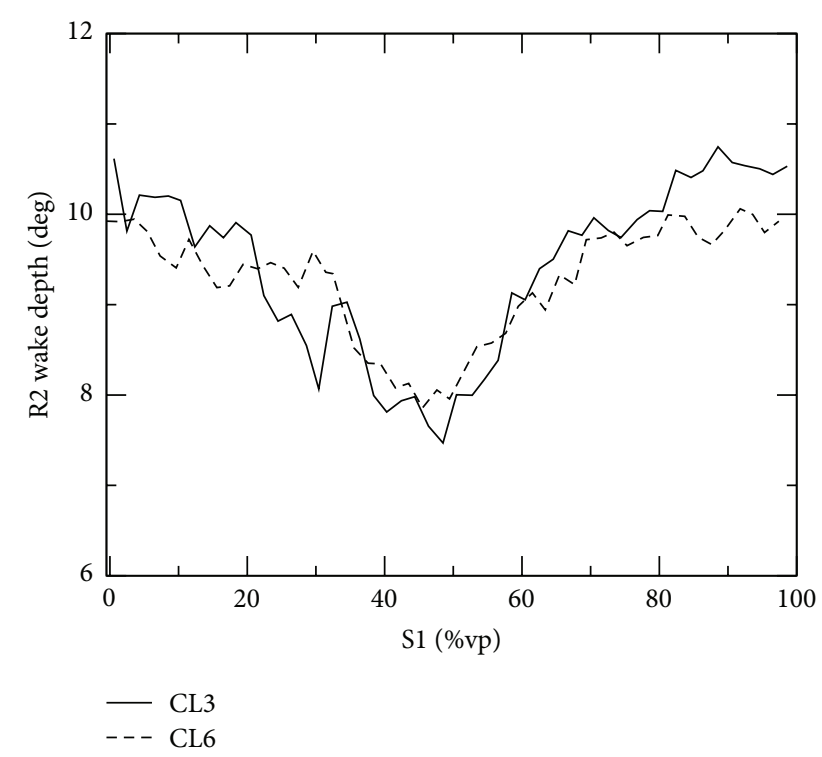

FIGURE 11: Rotor 2 wake depth at different locations across the vane passage.

Stator 1 wake in such a way that it has minimum adverse effects on the rotor boundary layer growth. For example, in Figure 9, the scenario on the left results in a smaller wake measurement than the scenario on the right because the effects of Stator 1 wake impingement on the suction side of the rotor are not triggering boundary layer separation. The range of ideal locations for Stator 1 wake impingement on the rotor suction surface will depend on the boundary layer development on the rotor suction side, and this can be influenced by many things, including the rotor's loading distribution, rotor leading edge shape, freestream turbulence intensity, and Reynolds number.

Rotor wake shapes have an important influence on the unsteady forcing of the downstream vane row. Thus, if an aeromechanics analysis was to be performed for a Campbell diagram crossing associated with the rotor wakes exciting a vibration mode on the downstream S2, a Fourier transform of the rotor wake may be computed to determine the energy associated with the frequency of a particular S2 vibrational mode. As the R2 wake shape changes, the amount of energy at that frequency will change. As Figure 11 shows, the rotor wake shape will change with respect to the upstream vane position. Thus, to determine accurate forcing function strength and to properly compare data between experiments and computations, the location at which the rotor wake data is accessed (with respect to the upstream vane) matters.

The standard deviation in averaging the 50 mean wakes measured at 50 points across the vane passage is shown in Figure 12. Clocking configuration CL6, shown with the dashed lines, has small peaks on either side of the wake centerline, which is near $50 \%$ of the rotor blade pass period. These peaks occur because of the wagging character of the wake associated with alternating shedding from the suction side and pressure side. The standard deviation off the suction side of the wake is slightly larger than that off of the pressure

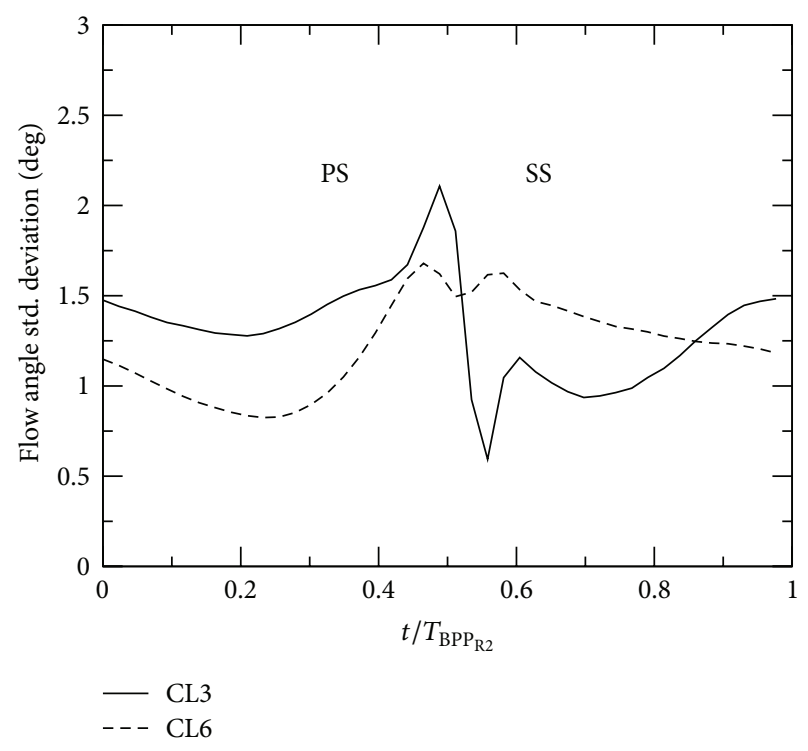

FIGURE 12: Standard deviation calculated by averaging the 50 mean wakes shown in Figure 10.

side of the wake. As shown in Figure 10, the suction side is experiencing impingement of Stator 1 wake, and this occurs at different points along Rotor 2 suction side for different circumferential probe locations across the vane passage. Thus, when averaging the 50 mean wakes, it is expected to see higher standard deviation associated with the suction side of the rotor wake.

This is not the trend observed for clocking configuration 3 , however. The levels of standard deviation are much larger on the pressure side of the wake. There are still peaks on each side of the wake centerline, but the pressure side peak is largest. The increased standard deviation on the pressure side of the wake for CL3 can be understood using Figure 13. Clocking configuration CL3 provides an interesting phase difference between Stator 1 and Stator 2 and it aligns Stator 1 wake with Stator 2 leading edge, whereas clocking configuration CL6 is half a passage out-of-phase with CL3 and locates Stator 1 wake in the middle of Stator 2 passage, as shown in Figure 10. Stator 1 wake appears to create a feedback mechanism that allows Stator 2 vane to influence the pressure side of Rotor 2 blade and wake leading to more variations associated with the pressure side shedding of the rotor blade.

\section{Conclusions}

Experiments were performed in a three-stage compressor to understand the effect of both the upstream vane and the downstream vane rows on the embedded rotor performance. Unsteady flow angle and total pressure measurements were acquired at a measurement plane halfway between Rotor 2 trailing edge and Stator 2 leading edge. The phase of the upstream and the downstream stator positions was adjusted using vane clocking. Thus, the effects of the rotor chopping the upstream Stator 1 wakes could be distinguished from the 


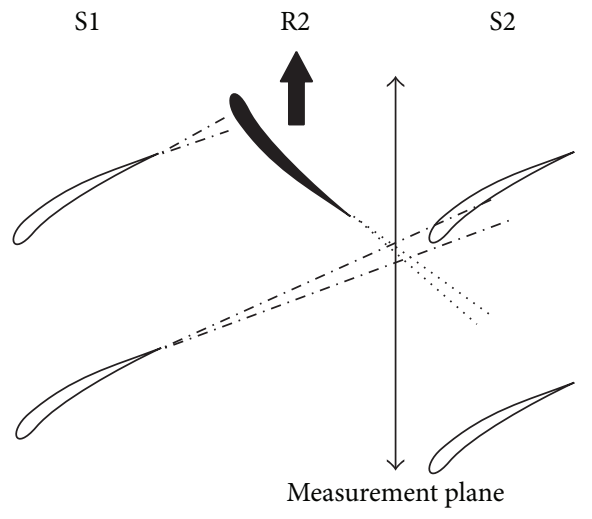

(a)

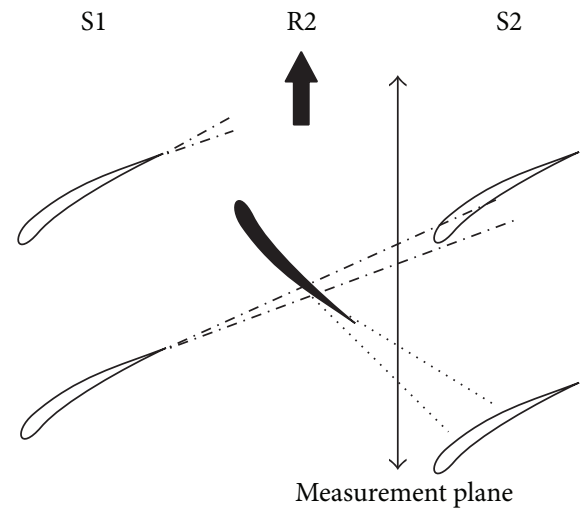

(b)

FIGURE 13: Cartoon showing S1 wake interactions with R2 and S2 representing configuration CL3.

effects of the potential field associated with the downstream Stator 2 leading edge.

The potential field associated with Stator 2 provides a flow angle change of 3-4 degrees across the vane passage. This is fairly uniform from $12 \%$ to $88 \%$ span where the measurements were acquired, with slightly less changes at $12 \%$ span. The absolute flow angle is the largest in the vicinity of Stator 2 leading edge. Since the static pressure is largest here, the rotor is back pressured when it passes by the vane leading edge and, thus, imparts more work on the flow. Also evident at this measurement plane were the remnants of Stator 1 wake as shown by a deficit in time-averaged stagnation pressure.

The mean flow angle and mean total pressure were compared for the two clocking configurations and the differences were negligible and within the measurement uncertainty. The passage average Rotor 2 wakes were also shown to be remarkably similar for the different relative positions of the downstream Stator 2 leading edge.

The mean Rotor 2 wake was calculated at 50 points across the vane passage for two different clocking configurations. The Rotor 2 wake depth was calculated at each circumferential location. The wake depth was not affected by the phasing or clocking of Stator 1 with respect to Stator 2. The wake depth did change by 3 degrees across the vane passage. This was attributed to Stator 1 wake interacting with different portions of Rotor 2 suction surface for different locations of the probe across the vane passage.

The standard deviation in the rotor wakes measured across the vane passage was very different for the two clocking configurations. This was attributed to the interaction between Stator 1 wake and Stator 2 leading edge present in clocking configuration 3. With Stator 1 wake impinging on the Stator 2 leading edge, there was an additional source of unsteadiness influencing the pressure side of Rotor 2 and its wake, leading to elevated levels of standard deviation in this region.

This compressor is representative of the rear stages of a high pressure compressor. Stages with higher Mach numbers or higher loadings could have stronger potential field effects, and in that case, the influence of the downsteram vane on the rotor exit flow field would be more significant. However, for this type of machine, these effects are of second-order compared to the influence of the upstream Stator 1 wake. Stator 1 wake has an important effect on Rotor 2 wake shape, which, as discussed, has implications when considering Campbell diagram crossings for forced response of Stator 2 vibrational modes that are excited by Rotor 2 . These types of blade row interaction data are not often presented in the open literature, and as multistage computational simulations increase in fidelity, accurately capturing these types of interactions becomes more important. Thus, these data provide an interesting and unique look at the effects of vane row interactions on rotor wake development.

\section{Nomenclature}

AR: Aspect ratio

bpp: Rotor blade-pass period

CL: Clocking configuration

EA: Phase-locked ensemble average

$P_{s}: \quad$ Static pressure

$P_{o 2}$ : Rotor 2 exit stagnation pressure

$P_{\mathrm{atm}}$ : Atmospheric pressure

R: $\quad$ Rotor

S: $\quad$ Stator

$t$ : Time

vp: Vane passage

$V_{\theta}$ : Absolute frame tangential velocity

$\alpha$ : Absolute flow angle.

\section{Conflict of Interests}

The author declares that there is no conflict of interests regarding the publication of this paper.

\section{Acknowledgments}

This research was funded in part by the Rolls-Royce Corporation and the State of Indiana 21st Century Research and Technology Fund. This support is most gratefully acknowledged. 


\section{References}

[1] R. Mailach and K. Vogeler, "Aerodynamic blade row interactions in an axial compressor-part II: unsteady profile pressure distribution and blade forces," ASME Journal of Turbomachinery, vol. 126, no. 1, pp. 45-51, 2004.

[2] E. J. Hall, "Aerodynamic modelling of multistage compressor flow fields part 1: analysis of rotor-stator-rotor aerodynamic interaction," Proceedings of the Institution of Mechanical Engineers G: Journal of Aerospace Engineering, vol. 212, no. 2, pp. 7789, 1998.

[3] M. B. Graf, E. M. Greitzer, F. E. Marble, and O. P. Sharma, "Effects of stator pressure field on upstream rotor performance," in Proceedings of the International Gas Turbine \& Aeroengine Congress, ASME Paper 99-GT-99, Indianapolis, Ind, USA, June 1999.

[4] C. Poensgen and H. E. Gallus, “Three-dimensional wake decay inside of a compressor cascade and its influence on the downstream unsteady flow field, part I: wake decay characteristics in the flow passage," ASME Journal of Turbomachinery, vol. 113, no. 2, pp. 180-189, 1991.

[5] W. S. Barankiewicz and M. D. Hathaway, "Effects of stator indexing on performance in a low speed multistage axial compressor," ASME Paper 97-GT-496, 1997.

[6] G. J. Walker, J. D. Hughes, I. Köhler, and W. J. Solomon, “The influence of Wake-wake interactions on loss fluctuations of a downstream axial compressor blade row," Journal of Turbomachinery, vol. 120, no. 4, pp. 695-704, 1998.

[7] V. E. Saren, N. M. Savin, D. J. Dorney, and R. M. Zacharias, "Experimental and numerical investigation of unsteady rotorstator interaction on axial compressor stage (with IGV) performance," in Unsteady Aerodynamics and Aeroelasticity of Turbomachines, Proceedings of the 8th International Symposium held in Stockholm, Sweden, 14-18 September 1997, pp. 407-424, Springer, 1997.

[8] N. L. Key, P. B. Lawless, and S. Fleeter, "An experimental study of vane clocking effects on embedded compressor stage performance," Journal of Turbomachinery, vol. 132, no. 1, Article ID 011018, 10 pages, 2010.

[9] V. R. Capece, S. R. Manwaring, and S. Fleeter, "Unsteady blade row interactions in a multistage compressor," AIAA Journal of Propulsion and Power, vol. 2, no. 2, pp. 168-174, 1986.

[10] Y. S. Choi, N. L. Key, and S. Fleeter, "Vane clocking effects on the resonant response of an embedded rotor," Journal of Propulsion and Power, vol. 27, no. 1, pp. 71-77, 2011.

[11] J. R. Salontay, N. L. Key, and R. D. Fulayter, "Investigation of flow physics of vane clocking effects on rotor resonant response," Journal of Propulsion and Power, vol. 27, no. 5, pp. 1001-1007, 2011.

[12] S. T. Hsu and A. M. Wo, "Reduction of unsteady blade loading by beneficial use of vortical and potential disturbances in an axial compressor with rotor clocking," ASME Journal of Turbomachinery, vol. 120, no. 4, pp. 705-713, 1998.

[13] V. E. Saren, N. M. Savin, D. J. Dorney, and D. L. Sondak, "Experimental and numerical investigation of airfoil clocking and interblade-row gap effects on axial compressor performance," AIAA Paper AIAA-98-3413, 1998.

[14] D. J. Dorney, D. L. Sondak, P. G. A. Cizmas, V. E. Saren, and N. M. Savin, "Full-annulus simulations of airfoil clocking in a compressor at off-design operating conditions," AIAA Paper 992383, 1999.
[15] R. D. Fulayter, An experimental investigation of resonant response of mistuned fan and compressor rotors utilizing NSMS [Ph.D. thesis], Department of Mechanical Engineering, Purdue University, West Lafayette, ind, USA, 2004.

[16] N. L. Key, P. B. Lawless, and S. Fleeter, "Vane clocking in a threestage compressor: frequency domain data analysis," Journal of Propulsion and Power, vol. 25, no. 5, pp. 1100-1107, 2009.

[17] N. L. Key, "Compressor vane clocking effects on embedded rotor performance," AIAA Journal of Propulsion and Power, vol. 30, no. 1, pp. 246-248, 2014.

[18] N. L. Key, P. B. Lawless, and S. Fleeter, "Rotor wake variability in a multistage compressor," AIAA Journal of Propulsion and Power, vol. 26, no. 2, pp. 344-352, 2010. 

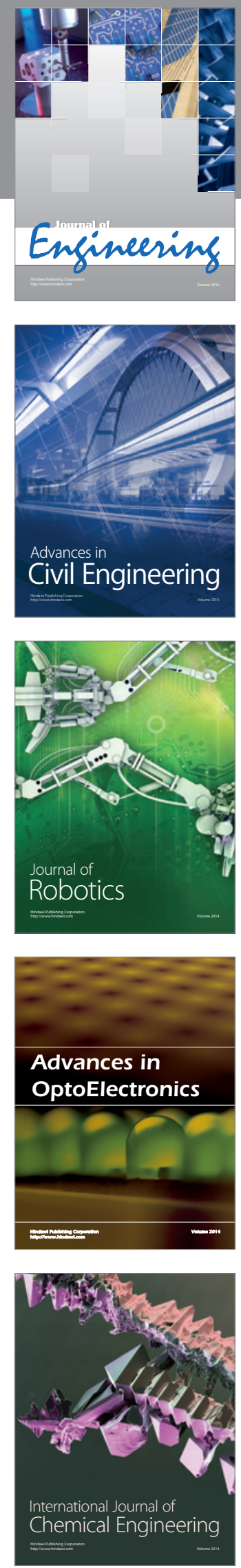

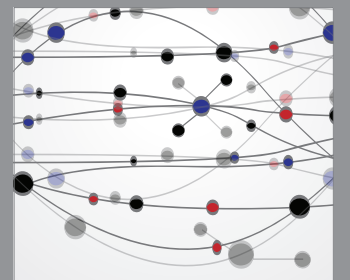

The Scientific World Journal
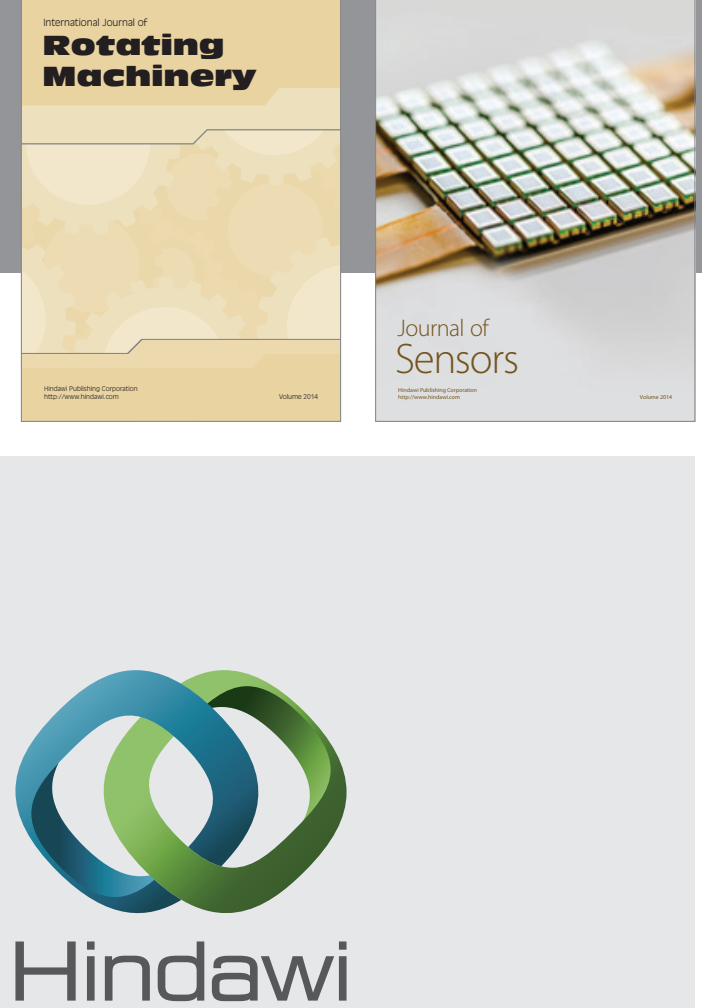

Submit your manuscripts at http://www.hindawi.com
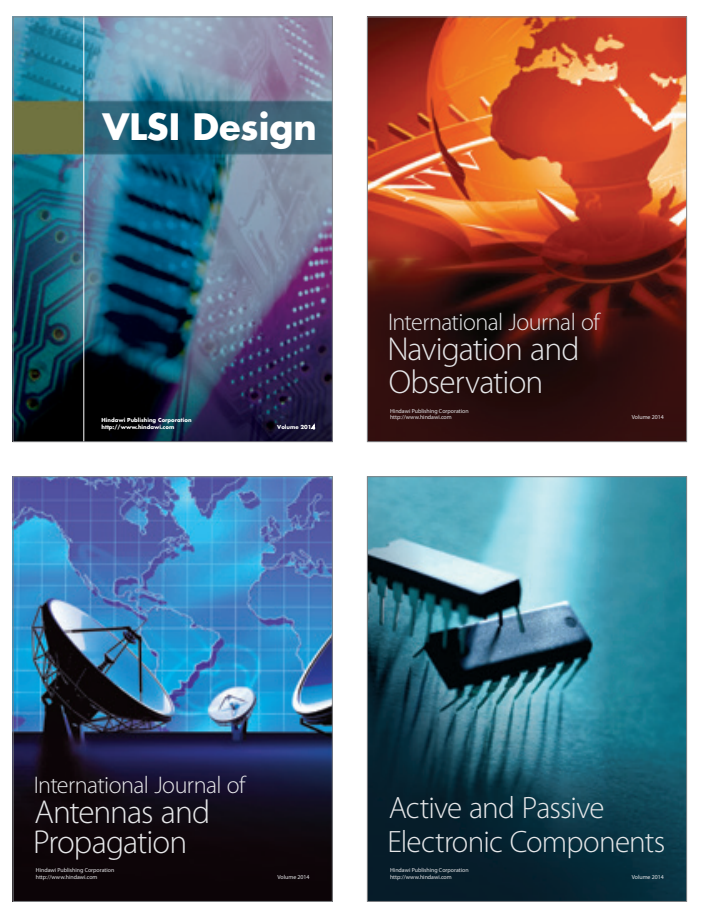
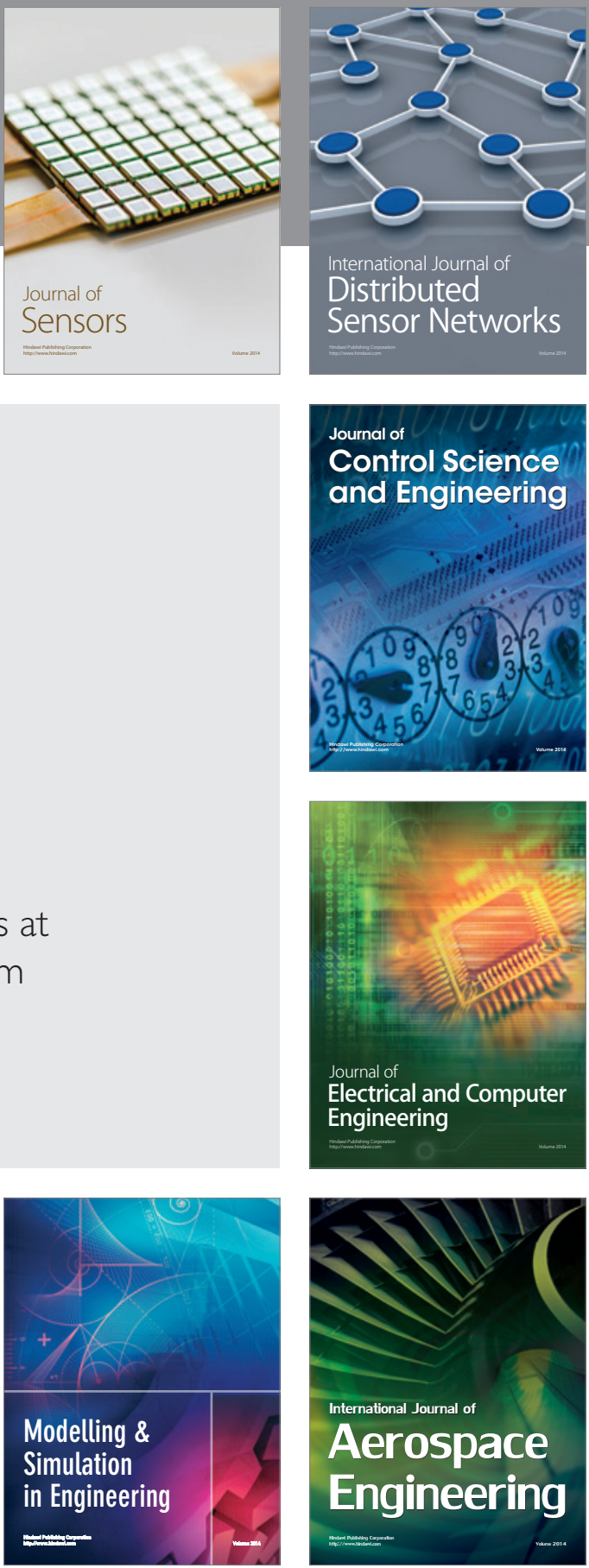

Journal of

Control Science

and Engineering
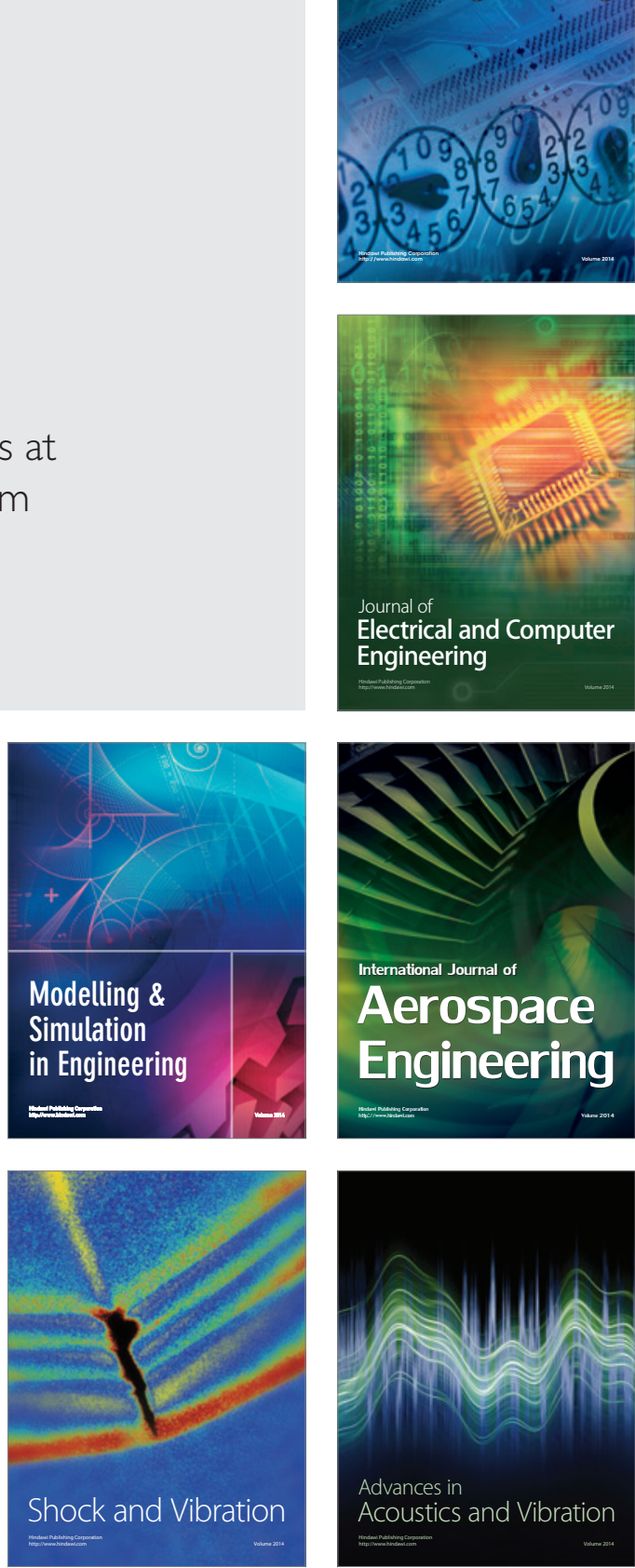